Arq. Bras. Med. Vet. Zootec., v.68, n.3, p.695-701, 2016

\title{
X-ray pelvimetry in common marmoset (Callithrix jacchus - LINNAEUS, 1758)
}

\author{
[Pelvimetria radiográfica em sagui-de-tufo-branco (Callithrix jacchus - LINNAEUS, 1758)] \\ L.L. Pinheiro ${ }^{1}$, A.R. Lima $^{1}$, P.P. Bombonato ${ }^{2}$, P.H.G. Castro $^{3}$, G.A. Silva ${ }^{3}$, \\ M.G.R. $\operatorname{Vaz}^{1}$, E. Branco ${ }^{1}$ \\ ${ }^{1}$ Universidade Federal Rural da Amazônia - Belém, PA \\ ${ }^{2}$ Faculdade de Medicina Veterinária e Zootecnia - Universidade de São Paulo - São Paulo, SP \\ ${ }^{3}$ Centro Nacional de Primatas - Instituto Evandro Chagas - Ananindeua, PA
}

\begin{abstract}
The common marmoset is an important Neotropical primate for biomedical research. With the intention of providing pelvimetric values that allow the selection of animals with better characteristics for reproduction, we studied the X-ray of the pelvis, in ventro-dorsal projection of 12 adult animals, six males and six females, belonging to the National Center of Primates - CENP. The measurements were made to right diagonal diameters (RDD), left diagonal diameter (LDD), bi-iliac middle diameter (BIMD), bi-iliac upper diameter (BIUD), bi-iliac lower diameter (BILD), sacrum-pubic diameter (SPD), and the input area of the pelvis (IAP), which were compared in relation to sex and bodily correlated with the biometrics. The results of the means and standard deviations regarding pelvimetry $(\mathrm{cm})$ were: for the RDD in males of $1.91 \pm 0.14$ and in the females of $2.05 \pm 0.08$; LDD in males of $1.85 \pm 0.16$ and in females of $2.03 \pm 0.08$; BIMD in males of $1.46 \pm 0.12$ and in the females of $1.5 \pm 0$; BIUD showed in males $1.3 \pm 0.1$ and in females of $1.3 \pm 0.06$; BILD in males of $1.35 \pm 0.15$ and in females of $1.25 \pm 0.08$; SPD in males of $1.68 \pm 0.09$ and in females of $1.93 \pm 0.13$; IAP in males of $1.9 \pm 0.26$ and in the females of $2.23 \pm 0.13$. It was concluded that the pelvis of Callithrix jacchus could be classified as dolicopelvic type, there is sexual dimorphism in relation to the pelvis of adult animals and that the bodily measurements have low positive correlation with pelvic measurements.
\end{abstract}

Keywords: radiology, pelvis, primates

\section{RESUMO}

O sagui-de-tufo-branco se destaca como um importante primata neotropical para as pesquisas biomédicas. Com o intuito de fornecer valores pelvimétricos que permitam a seleção de animais com melhores características para a reprodução, estudaram-se radiografias da pelve, em projeção ventrodorsal, de 12 animais, sendo seis machos e seis fêmeas, adultos, pertencentes ao Centro Nacional de Primatas - CENP. As mensurações realizadas foram referentes aos diâmetros diagonal direito (DDD), diagonal esquerdo (DDE), bi-ilíaco médio (DBIM), bi-ilíaco superior (DBIS), bi-ilíaco inferior (DBII), sacropúbico (DSP), além da área de entrada da pelve (AEP), os quais foram comparados em relação ao sexo e correlacionados com a biometria corpórea. Os resultados de médias e desvios-padrão

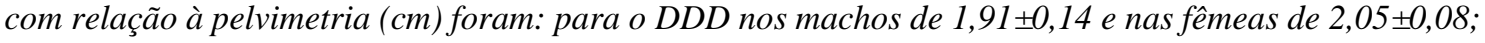

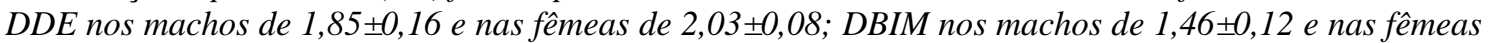

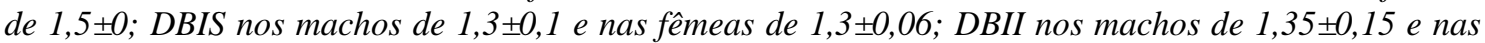

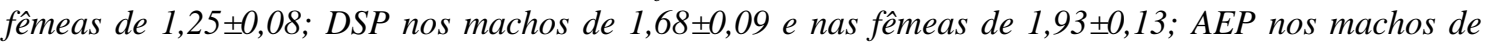

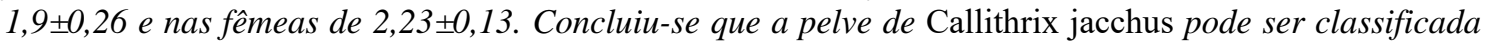
como do tipo dolicopélvica, existe dimorfismo sexual em relação às pelves de animais adultos e que as medidas corpóreas apresentam baixa correlação positiva com as medidas pélvicas.

Palavras-chave: radiologia, pelve, primatas

Recebido em 10 de junho de 2015

Aceito em 14 de dezembro de 2015

E-mail: luanelopespinheiro@gmail.com 


\section{INTRODUCTION}

The Neotropical primates have an important role regarding the phylogenetic proximity with the human being, which, due to their size and easy handling, are currently important models for biomedical research (Ward and Vallender, 2012). The availability of these animals is certainly one of the main contributors to the rise of Brazil in the international community of biomedical research. Based on productivity over the last decade, Brazil leads major countries such as Japan, France and England in relation to the number of published articles that use models of non-human primates (Torres et al., 2010).

The Callithrix jacchus, popularly known as common marmoset it is a specie of Brazilian origin that fits very well in captivity, where due to the lower maintenance cost in relation to other primates, facilitated management, biosafety and physiological peculiarities, the number of animal rooms dedicated to species and their use expanded in the areas of research has increased (Mansfield, 2003).

With the growing demand of these animals, the search for biological information of the species has increased significantly since the anatomy to clinical medicine, enabling the permanence in captivity and expanding information bases for interpretations of experiments (Ward and Vallender, 2012).

The measurement of pelvic diameters directly on the radiographic film is a technique known as $\mathrm{x}$ ray pelvimetry and has been used mainly in small animals such as dogs (Eneroth and Haugey, 1999; Páfaro, 2007), cats (Páfaro et al., 2007; Celimli et al., 2008) and other non-human primates (Ramadinha, 2003; Valle et al., 2006). Its use is directly related to reproduction, allowing the prediction or avoidance of difficulties at birth (Derivaux and Ectors, 1984).

In this regard, this study aimed to perform pelvic measurements of common marmoset (Callithrix jacchus), by means of x-ray study, to obtain data that allow the anatomical classification of the pelvis, and that assist in the selection of individuals for reproduction, allowing the exclusion of those with pelvic diameters that adversely affect delivery.

\section{MATERIALS AND METHODS}

This study followed the ethical principles of animal experiments adopted by the Brazilian College of Animal Experimentation (COBEA) and was approved by the Ethics Committee on Animal Use (CEUA), protocol no. 015/2010.

12 animals were used, being 6 males and 6 non pregnant females, adults, of the Callithrix jacchus specie (Linnaeus, 1758), belonging to the National Center of Primates -CENP located in Ananindua, Pará

The animals were contained manually by the attendant with the aid of leather gloves, and, subsequently, sedated with the use of an anesthetic composed of association of tiletamine $(125 \mathrm{mg})$ and zolazepam hydrochloride $(125 \mathrm{mg})$ at a dosage of $0.1 \mathrm{~mL} / 300 \mathrm{~g}$ live weight, by intramuscular injection, in order to remain sedated during all procedures (weighing, body biometrics and X-rays) according to Ludlage and Mansfield (2003).

The weighing was performed using digital scales, and then taking the biometric measurements obtained with standardized metric tape, the length of the body, circumference of the skull, chest circumference, pelvis circumference and tail length (Fig. 1A and 1B).

The radiographs of the pelvis were performed in ventro-dorsal projection (Fig. 1C), using a radiographic apparatus brand Intecal $\AA$, model $\mathrm{CR}-7$ and power of $100 \mathrm{KV}$ and $100 \mathrm{~mA}$. A $3 \mathrm{~cm}$ thickness sponge was used between the animal and the chassis to obtain a better picture, and a $2.0 \mathrm{~cm}$ width and $2.0 \mathrm{~cm}$ length metal plate was placed near the animal, providing a parameter to correct the projection differences.

With the $\mathrm{x}$-ray images visualized in a light box, the following measurements were performed using a transparent millimeter ruler: bi-iliac upper diameter (BIUD), bi-iliac lower diameter (BILD), bi-iliac middle diameter (BIMD), right diagonal diameter (RDD), left diagonal diameter (LDD) and sacrum-pubic diameter (SPD), in addition to the input area of the pelvis (IAP).

Such measurements were carried out according to Ramadinha (2003), as follows: bi-iliac upper diameter (BIUD) by drawing a straight-line transverse to the longitudinal diameter of the 
pelvis in the shortest diameter of sacrum-iliac articulation. The bi-iliac lower diameter (BILD), by drawing a straight line parallel to the diameter $\mathrm{AB}$, this being measured at the ilio-pubic junction. Two diameters were measured diagonally, the right that goes from point $A$ to $D$ and the left that starts at point $\mathrm{B}$ and goes up to the $\mathrm{C}$ at the intersection point of the diagonal and parallel diameters to the bi-iliac upper diameter and to the bi-iliac lower diameter the third transverse diameter was traced, i.e. the bi-iliac medium diameter (BIMD), which goes from the medial surface of the right to left ilium. The sacrum-pubic diameter (SPD) was taken from the central point of the bi-iliac upper diameter until the cranial portion of the pubic symphysis (Figure 1D).

The inlet area of the pelvis (IAP) was calculated according to Oliveira et al. (2003), by means of the formula IAP $=($ bi-iliac medium diameter $/ 2)$ $\mathrm{X}$ (sacrum-pubic diameter/2) $\mathrm{X} \pi$.

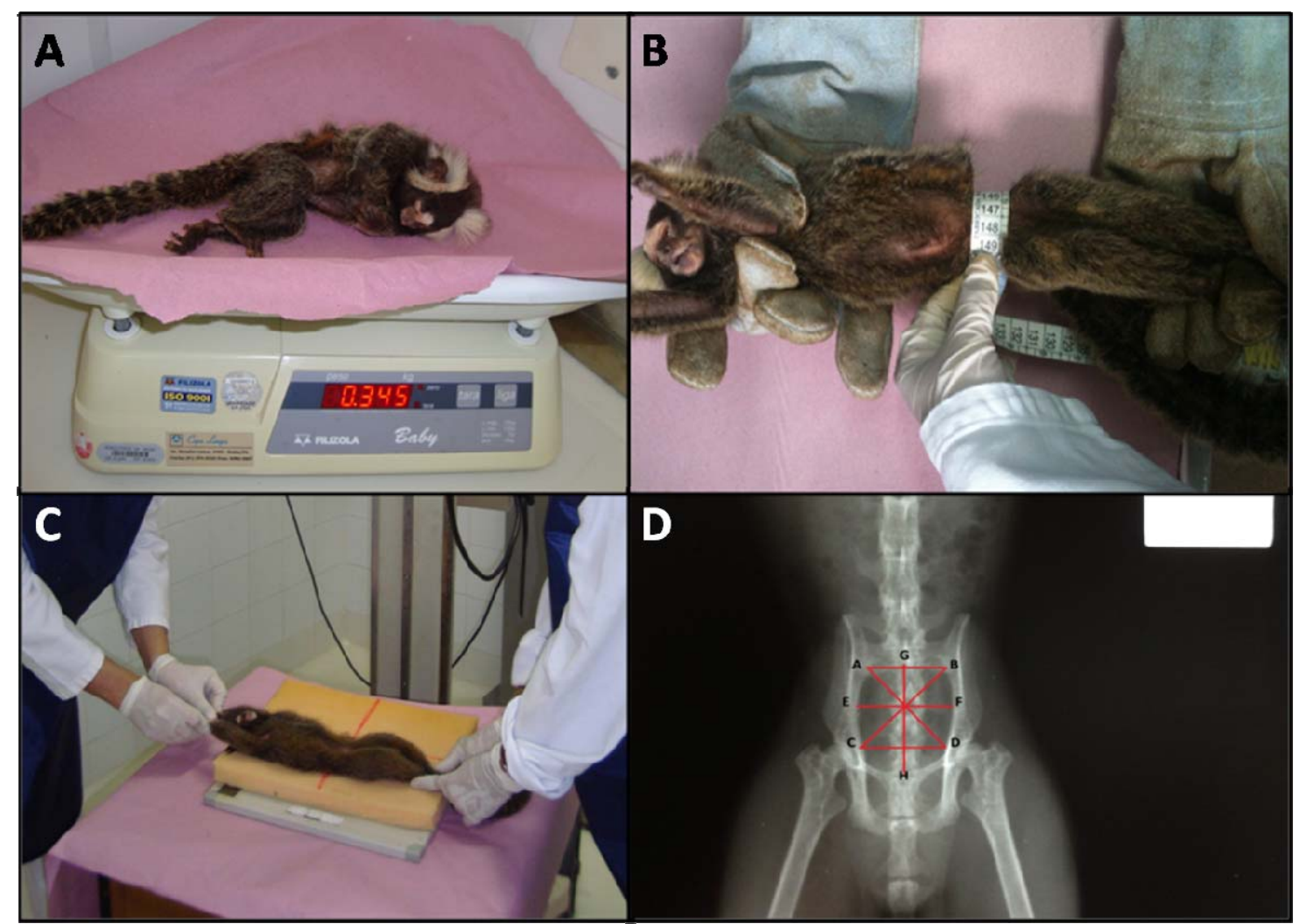

Figure 1. A- Weighing; B- Implementation of biometric circumference of the pelvis; C- Radiographic examination in ventro-dorsal projection of a common marmoset (Callithrix jacchus), in CENP, Ananindeua, Pará; D - Photography of pelvis radiography, with marking of diameters studied: AB - biiliac upper diameter, CD - bi-iliac lower diameter, EF - bi-iliac middle diameter, AD - right diagonal diameter, $\mathrm{BC}$ - left diagonal diameter and GH - sacrum-pubic diameter.

The values obtained for measures of central tendency, calculation of variance and Pearson's correlation were subjected to statistical analysis, according to Ramadinha (2003), using the GraphPad Instat statistical program. We used the Tukey test for the comparison of the effects of the gender variable $(M$ and $F$ ) on the variables BIUD, BIMD, RDD, LDD, SPD and IAP.
The evaluation of statistical correlations between the biometric measurements (weight, body length, skull circumference, chest circumference, pelvic circumference and tail length) with the pelvimetric radiographic measures (BIUD, BILD, RDD, LDD, SPD and IAP) were performed by calculating the respective Pearson's correlation coefficients for all the possible 
combinations. For all tests the differences were considered significant when $\mathrm{P}<0.05$.

\section{RESULTS}

In the 12 animals studied, the average values, standard deviation, minimum and maximum for the body biometrics and the radiographic pelvimetry are presented in Tab. 1 and 2 .

The analysis of variance for Tukey test showed statistically significant differences when compared the sex of animals in relation to IAP $(\mathrm{P}<0.01)$.

Table 1. Values related to body biometrics $(\mathrm{cm})$ of common marmoset males and females (Callithrix jacchus)

\begin{tabular}{|c|c|c|c|c|c|c|c|c|c|c|c|c|c|}
\hline \multicolumn{2}{|l|}{ Tatoo } & \multicolumn{2}{|c|}{ Weight } & \multicolumn{2}{|c|}{ Body } & \multicolumn{2}{|c|}{ Skull } & \multicolumn{2}{|c|}{ Thorax } & \multicolumn{2}{|c|}{ Pelvis } & \multicolumn{2}{|l|}{ Tail } \\
\hline M & $\mathrm{F}$ & $\mathrm{M}$ & $\mathrm{F}$ & $\mathrm{M}$ & $\mathrm{F}$ & M & $\mathrm{F}$ & $\mathrm{M}$ & $\mathrm{F}$ & $\mathrm{M}$ & $\mathrm{F}$ & $\mathrm{M}$ & $\mathrm{F}$ \\
\hline AD-BBE & AD-BDG & 355 & 365 & 20.5 & 20 & 10 & 14 & 14 & 15 & 12.5 & 11 & 31 & 29 \\
\hline AD-BBR & AD-BDH & 330 & 325 & 21 & 21 & 12.8 & 13 & 13 & 13.5 & 11 & 9.8 & 26 & 16 \\
\hline AD-BDB & AD-BDM & 465 & 345 & 20 & 20.3 & 13.5 & 12.6 & 16 & 14 & 12.7 & 10.3 & 28 & 32.3 \\
\hline AD-BDF & AD-BDP & 310 & 235 & 20 & 19 & 13 & 12 & 14 & 13.5 & 11.4 & 9.7 & 27 & 30 \\
\hline AD-BDI & AD-BDT & 290 & 355 & 21.5 & 21.5 & 13.5 & 12.4 & 13.8 & 12.2 & 9.5 & 9.1 & 29 & 33.6 \\
\hline AD-BDS & AD-BDU & 255 & 325 & 18.5 & 22 & 13.3 & 12.3 & 12.5 & 14 & 11.3 & 11.6 & 28.5 & 34 \\
\hline Average & & 334.2 & 325 & 20.2 & 20.6 & 13.2 & 12.7 & 13.9 & 13.7 & 11.4 & 10.2 & 28.2 & 29.1 \\
\hline SD & & 72.6 & 46.9 & 1 & 1 & 0.2 & 0.7 & 1.2 & 0.9 & 1.1 & 0.9 & 1.7 & 3.5 \\
\hline Maximum & & 465 & 365 & 21.5 & 21.5 & 13.5 & 14 & 13.8 & 15 & 12.7 & 11.6 & 31 & 34 \\
\hline Minimum & & 255 & 235 & 18.5 & 20 & 12.8 & 12 & 12.5 & 12.2 & 9.5 & 9.1 & 26 & 16 \\
\hline
\end{tabular}

M - male; F - female; SD - standard deviation.

Table 2. Values related to radiographic pelvimetry $(\mathrm{cm})$ of common marmoset males and females (Callithrix jacchus)

\begin{tabular}{|c|c|c|c|c|c|c|c|c|c|c|c|c|c|c|c|}
\hline \multicolumn{2}{|l|}{ Tatoo } & \multicolumn{2}{|c|}{ RDD } & \multicolumn{2}{|c|}{ LDD } & \multicolumn{2}{|c|}{ BIMD } & \multicolumn{2}{|c|}{ BIUD } & \multicolumn{2}{|c|}{ BILD } & \multicolumn{2}{|l|}{ SPD } & \multicolumn{2}{|l|}{ IAP } \\
\hline M & $\mathrm{F}$ & M & $\mathrm{F}$ & M & $\mathrm{F}$ & M & $\mathrm{F}$ & M & $\mathrm{F}$ & M & $\mathrm{F}$ & M & $\mathrm{F}$ & M & $\mathrm{F}$ \\
\hline AD-BBE & AD-BDG & 2.1 & 1.9 & 2.1 & 1.9 & 1.6 & 1.5 & 1.5 & 1.2 & 1.6 & 1.3 & 1.8 & 1.7 & 2.2 & 2.0 \\
\hline AD-BDB & AD-BDM & 2.0 & 2.1 & 1.9 & 2.1 & 1.6 & 1.5 & 1.3 & 1.4 & 1.4 & 1.3 & 1.8 & 1.9 & 2.2 & 2.2 \\
\hline AD-BDF & AD-BDP & 1.9 & 2.1 & 1.8 & 2.1 & 1.4 & 1.5 & 1.2 & 1.3 & 1.2 & 1.2 & 1.6 & 2.1 & 1.7 & 2.4 \\
\hline AD-BDS & AD-BDU & 1.8 & 2.1 & 1.8 & 2.0 & 1.4 & 1.5 & 1.3 & 1.3 & 1.3 & 1.3 & 1.6 & 1.9 & 1.7 & 2.2 \\
\hline Average & & 1.91 & 2.05 & 1.85 & 2.03 & 146 & 1.5 & 1.3 & 1.3 & 1.35 & 1.25 & 1.68 & 1.93 & 1.9 & 2.23 \\
\hline SD & & 0.14 & 0.08 & 0.16 & 0.08 & 0.12 & 0 & 0.1 & 0.06 & 0.15 & 0.08 & 0.09 & 0.13 & 0.26 & 0.13 \\
\hline Maximum & & 2.1 & 2.1 & 2.1 & 2.1 & 1.6 & 1.5 & 1.5 & 1.4 & 1.6 & 1.3 & 1.8 & 1.0 & 2.2 & 2.4 \\
\hline
\end{tabular}

M - male; F - female; SD - standard deviation; RDD - diameter diagonal right; LDD - left diagonal diameter; BIMD bi-iliac middle diameter; BIUD - aortobi-iliac upper diameter; BILD - bi-iliac lower diameter; SPD - sacrum-pubic diameter; IAP - input area of the pelvis.

The analysis for verification of the existence or not of a correlation between the variables by the Pearson's coefficient correlation statistical method showedpositive and negative correlation for some variables evaluated, presented in Table 3,4 and 5. 
Table 3. Values regarding the coefficient of correlation (R) between the different pelvic diameters of common marmoset (Callithrix jacchus)

\begin{tabular}{llllllll}
\hline & RDD & LDD & BIMD & BIUD & BILD & SPD & IAP \\
\hline RDD & 1.0000 & 0.9490 & 0.7872 & 0.6378 & 0.3189 & 0.7926 & 0.8983 \\
LDD & 0.9490 & 1.0000 & 0.7541 & 0.6815 & 0.2726 & 0.8259 & 0.9055 \\
BIMD & 0.7872 & 0.7541 & 1.0000 & 0.6384 & 0.5959 & 0.5141 & 0.7872 \\
BIUD & 0.6378 & 0.6815 & 0.6384 & 1.0000 & 0.6667 & 0.3697 & 0.5182 \\
BILD & 0.3189 & 0.2726 & 0.5959 & 0.6667 & 1.0000 & -0.1643 & 0.1329 \\
SPD & 0.7926 & 0.8259 & 0.5141 & 0.3697 & -0.1643 & 1.0000 & 0.9302 \\
IAP & 0.8983 & 0.9055 & 0.7872 & 0.5182 & 0.1329 & 0.9302 & 1.0000 \\
\hline
\end{tabular}

RDD - right diagonal diameter; LDD - left diagonal diameter; BIMD - bi-iliac middle diameter; BIUD - bi-iliac upper diameter; BILD - bi-iliac lower diameter; SPD - sacrum-pubic diameter; IAP - input area of the pelvis.

Table 4. Values regarding the coefficient of correlation (R) between the measures of the body biometry of common marmoset (Callithrix jacchus)

\begin{tabular}{lllllll}
\hline & Weight & Body & Tail & Skull & Thorax & Pelvis \\
\hline Weight & 1.0000 & 0.2846 & 0.0332 & 0.3724 & 0.6526 & 0.4869 \\
Body & 0.2846 & 1.0000 & 0.0790 & -0.1620 & -0.0555 & -0.2106 \\
Tail & 0.0332 & 0.0790 & 1.0000 & -0.2967 & -0.0241 & 0.0991 \\
Skull & 0.3724 & -0.1620 & -0.2967 & 1.0000 & 0.4817 & 0.3256 \\
Thorax & 0.6526 & -0.0555 & -0.0241 & 0.4817 & 1.0000 & 0.5721 \\
Pelvis & 0.4869 & -0.2106 & 0.0991 & 0.3256 & 0.5721 & 1.0000 \\
\hline
\end{tabular}

Table 5. Values regarding the coefficient of correlation (R) between the different pelvic diameters and the measures of the body biometry in common marmoset (Callithrix jacchus)

\begin{tabular}{llllllll}
\hline & RDD & LDD & BIMD & BIUD & BILD & SPD & IAP \\
\hline Weight & 0.2199 & 0.1163 & 0.6222 & 0.1640 & 0.3828 & 0.0004 & 0.2722 \\
Body & 0.1436 & -0.0061 & -0.0123 & -0.0206 & -0.0688 & 0.1453 & 0.1338 \\
Tail & 0.0101 & 0.0025 & 0.0670 & 0.2104 & -0.0935 & 0.0312 & 0.0527 \\
Skull & -0.6290 & -0.5732 & -0.1711 & -0.3536 & 0.2481 & -0.7018 & -0.5687 \\
Thorax & 0.0787 & -0.0374 & 0.3708 & -0.0834 & 0.3682 & -0.1280 & 0.0687 \\
Pelvi & 0.1199 & -0.0012 & 0.4825 & 0.3118 & 0.7581 & -0.3809 & -0.0877 \\
\hline
\end{tabular}

RDD - right diagonal diameter; LDD - left diagonal diameter; BIMD - bi-iliac middle diameter; BIUD - bi-iliac upper diameter; BILD - bi-iliac lower diameter; SPD - sacrum-pubic diameter; IAP - input area of the pelvis.

\section{DISCUSSION}

Among the various species used in biomedical research, the common marmoset (Callithrix jacchus) stands out as an excellent experimental model. Stevenson and Rylands (1988) cite, among other things, its high prolificacy as one of the reasons for the increase in the use of this species.

In relation to the data obtained from the biometrics body, it was noted that the results referring to weight, body and tail length were similar to those reported by Stevenson and Rylands (1988), Clarke (1994) and Auricchio (1995) for this species.

May and Harrison (1994) mention that the radiographic ventro-dorsal projection of the pelvis is the best to identify problems in this region, and also inform that the lateral position is of little value in the assessment of the pelvis. We used the ventro-dorsal projection, as well as Eneroth and Haugey (1999) in dogs of Boston Terrier and Scottish Terrier breeds, Ramadinha (2003) in tamarins (Leontopithecus rosalia, 
Leontopithecus chrysomelas and Leontopithecus chrysopygus), Valle et al. (2006) in owl monkeys (Aotus azarai infulatus) and Páfaro (2007) in different breeds of dogs.

In relation to the pelvis shape, the data obtained from radiographic pelvimetry showed that the biiliac medium diameters are smaller than the sacrum-pubic diameters, both in males and in females, which classifies the pelvis of common marmoset as the dolicopelvica type, similar to ruminants (Oliveira et al., 2003), tamarins (Leontopithecus sp) (Ramadinha, 2003), owl monkeys (Aotus azarai infulatus) (Valle et al. 2006) and the dogs of Pinscher, Poodle, Teckel and SRD breeds (Páfaro, 2007). Differing from feline adult SRD (Páfaro et al., 2007), dogs of Brazilian Fila, German Shepherd and Rottweiler breeds (Páfaro, 2007) in which the pelvis is classified as mesatipelvic.

With the exception of bi-iliac lower diameter, all the diameter means were larger in females when compared to males, similar to that reported by Valle et al. (2006) in the owl monkey, however, in this, all the pelvic averages were higher in females. Unlike what Ramadinha (2003) mentions for tamarins which have higher bi-iliac upper and lower diameters in males than in females.

As reported by Valle et al. (2006) in owl monkey and Ramadinha (2003) in three species of tamarins (Leontopithecus rosalia, Leontopithecus chrysomelas and Leontopithecus chrysopygus), the input area of the pelvis was higher in females than in males. Schultz (1949), in relation to chimpanzees, mentions that this index presents a considerable difference in the averages in relation to sex, where the enlargement of the pelvis of the female represents an adaptation for vital requirements of childbirth.

When the sex of animals is considered, the variance analysis indicates there are statistically significant differences in relation to the input area of the pelvis, which differs from the findings of Valle et al. (2006) in owl monkeys, which indicate no significant differences between males and females in relation to left diagonal diameter, bi-iliac middle diameter, biiliac upper diameter, bi-iliac lower diameter, sacrum-pubic diameter and input area of the pelvis. This also differs from the results of
Ramadinha (2003) in tamarins, which says there are significant differences between the sex of animals and all pelvic diameters, except the biiliac lower diameter.

The results obtained from the analysis of correlations indicate positive correlations of high intensity between the right diagonal diameter and left diagonal diameter, bi-iliac medium diameter, bi-iliac upper diameter, sacrum-pubic diameter and the input area of the pelvis; between the left diagonal diameter and the bi-iliac medium diameter, bi-iliac upper diameter, sacrum-pubic diameter and the input area of the pelvis; between the diameter bi-iliac middle and upper bi-iliac weight, diameter and the input area of the pelvis; between the bi-iliac upper diameter and bi-iliac lower diameter; between the bi-iliac lower diameter and the pelvis; and the sacrumpubic diameter and the input area of the pelvis. The results presented by Valle et al. (2006) in owl monkeys are similar regarding the positive correlations of high intensity, between the left diagonal diameter and the bi-iliac middle diameter, sacrum-pubic diameter and the input area of the pelvis; between the bi-iliac medium diameter and the input area of the pelvis and sacrum-pubic diameter and the input area of the pelvis. Ramadinha (2003), in tamarins, reports positive correlations of high intensity only between the sacrum-pubic diameter and input area of the pelvis.

In a general way, in common marmoset, the pelvic measurements and the measurements of body biometrics presented in its most positive correlations of low intensity, thus, we corroborate with the results presented by Valle et al. (2006) where it can be suggested that the body biometrics does not have significant value to predict the pelvic measurements.

Finally, pelvimetric studies have been performed in different species with the approach to the prevention of tocologics problems employed in the selection of animals in programs of reproductive management. In a retrospective study of a colony of Callithrix jacchus, in 294 births a perinatal mortality rate of $20.6 \%$ was observed (ROTHE et al. 1992). Richter (1984) cites 11 dystocias in 1,046 births of callitrichideos. The most frequent causes, according to Johnson-Delaney (1994), are large fetuses and occurrence of posterior presentation. 
Despite the difficult occurrence of dystocic deliveries observed in captivity in these animals, the radiographic pelvimetry makes it possible to obtain morphological data that act to aid in the selection of breeding stock, in addition to the classification of the pelvis as the form.

\section{CONCLUSIONS}

The results of pelvic diameters allow the classification of the pelvis of common marmoset (Callithrix jacchus) as dolicopelvic by homoplasia existing between this species and some breeds of dogs; there is sexual dimorphism in adults, and differences are statistically significant when sex was considered, in relation to the input area of the pelvis; and the body biometric measurements presented their most positive correlations of low intensity with the pelvic measurements.

\section{ACKNOWLEDGMENTS}

The National Center of Primates (CENP), Secretary of Health Surveillance (SVS), Ministry of Health $(\mathrm{MOH})$, for their support in carrying out this work.

\section{REFERENCES}

AURICCHIO, P. (Ed). Primatas do Brasil. São Paulo: Terra Brasilis, 1995. 168p.

CELIMLI, N.; INTAS, D.S.; YILMAZBAS, G. et al. Radiographic pelvimetry and evaluation of radiographic findings of the pelvis in cats with dystocia. Tierärztl. Prax. K., v.4, p.277-284, 2008.

CLARKE, J.M. The common marmoset (Callithrix jacchus). Anzccart N., v.7, p.1-8, 1994.

DERIVAUX, J.; ECTORS, F. (Ed). Fisiopatologia de la gestacion y obstetricia veterinária. Zaragoza: Acribia, 1984. 277p.

ENEROTH, S.W.P.; HAUGEY, K.G. Radiographic pelvimetry for assessment of dystocia in bitches: a clinical study in two terrier breeds. J. Small. Anim. Pract., v.40, p.257-264, 1999.

JOHNSON-DELANEY, E.A. Primates, In: QUESENBERY, K.; HILLYER, E.V. (Eds.). Exotic pet medicine II. Philadelphia: Saunders, v.24, 1994, p.121-156.

LUDLAGE, E.; MANSFIELD, K. Clinical care and diseases of the common marmoset (Callithrix jacchus). Comp. Med., v.53, p.369-382, 2003.
MAY, S.A.; HARISSON, L. Radiography of the hip and pelvis. Equine Vet. Educ., v.6, p.152-153, 1994.

MANSFIELD, K. Marmoset models commonly used in biomedical research. Comp. Med., v.53, p.383-392, 2003.

OLIVEIRA, P.C.; BOMBONATO, P.P.; BALIEIRO, J.C.C. Pelvimetry in females Nelore. Braz. J. Vet. Res. Anim. Sci., v.40, p.297-304, 2003.

PÁFARO, V. Pelvimetria radiográfica em diferentes raças de fêmeas caninas adultas (Canis Familiaris Linnaeus, 1758). 2007. 38f. Dissertação (Mestrado em Cirurgia Veterinária) - Faculdade de Medicina Veterinária e Zootecnia, Universidade Estadual Paulista Júlio de Mesquita Filho, Jaboticabal, SP

PÁFARO, V.; ZANATTA, R.; CANOLA, J.C. et al. Pelvimetria radiográfica em fêmeas felinas. Acta. Sci. Vet., v.35, p.558-559, 2007.

RAMADINHA, L.S. Pelvimetria em micos leões. 2003. 59f. Tese (Doutorado em Anatomia dos Animais Domésticos) - Faculdade de Medicina Veterinária e Zootecnia, Universidade de São Paulo, São Paulo, SP.

RICHTER, E.B. Biology and diseases of Callitrichidae. In: FAX, G.; COHEN, B.J.; LOEW, F.M. (Eds.). Laboratory animal medicine. Sam Diego: Academic Press, 1984. p.353-383.

ROTHE, H.; DARMS, K.; KOENING, A. Sex ratio and mortality in a laboratory colon y of the common marmosel (Callithrix jacchus). J. Lab. Anim., v.26, p.88-99, 1992.

SCHULTZ, A.H. Sex differences in the pelvis of primates. J. Physiol. Anthropol., v.7, p.401-423, 1949.

STEVENSON, M.F.; RYLANDS, A.B. The Marmosets, genus Callithrix. In: MITTERMEIER, A.B.; RYLANDS, A.B.; COIMBRA-FILHO, A.; FONSECA, G.A.B. (Eds.). Ecology and behavior of neotropical primates. Contagem: Littera Maciel Ltda, 1988. V.2, p.131-222.

TORRES, L.B.; ARAUJO, B.H.S.; CASTRO, P.H.G. et al. The use of New World primates for biomedical research: an overview of the last four decades. $J$. Primatol., v.72, p.1055-1061, 2010.

VALLE, C.M.R.; VALLE, R.R.; MONTEIRO, F.O.B. et al. Pelvimetria em macacos-da-noite (Aotus azarai infulatus - KUHL, 1850). Braz. J. Vet. Res. Anim. Sci., v.43, p.370-378, 2006.

WARD, J.M.; VALLENDER, E.J. The resurgence and genetic implications of New World primates in biomedical research. Trends Genet., v.28, p.586-91, 2012. 